\title{
A Note on the Texts
}

For each of the selections included herein, I have used the texts which, as prepared in accordance with the principles of the Center for Editions of American Authors of the Modern Language Association of America, were published by the University of California Press in the Mark Twain Papers Series volumes Which Was the Dream? and Fables of Man. The appendices of those volumes, as well as most of the editorial notes, have been omitted from this book to provide a clear reading text. I have chosen the following writings of Samuel L. Clemens-Mark Twain:

From Which Was the Dream?

"The Passenger's Story"

"The Enchanted Sea-Wilderness"

"Which Was the Dream?"

"The Great Dark"

"The Mad Passenger"

"Which Was It" (excerpt)

"Three Thousand Years Among the Microbes"

From Fables of Man

"Little Bessie"

"Little Nelly Tells a Story Out of Her Own Head"

"The Ten Coinmandments"

"Thoughts of God"

"The Synod of Praise"

"The Refuge of the Derelicts"

"The Fable of the Yellow Terror"

"Passage from 'Glances at History' (suppressed.) Date, 9th century"

'Passage from 'Outlines of History' (suppressed.) Date, 9th century" 
viii

A Note on the Texts

"Passage from a Lecture"

"History 1,000 Years from Now"

"Old Age"

Dates of Mark Twain's composition are given in parentheses at the end of each selection.

J. S. T. 